\title{
Eptifibatide: The evidence for its role in the management of acute coronary syndromes [Corrigendum]
}

\author{
Shah I, Khan SO, Malhotra S, Fischell T. Core Evidence. \\ 2009;4:49-65.
}

Note that on pages 56 and 57, in the legends of both Table 3 and Table 4, the definition of TIMI is incorrectly stated as "TIMI, thrombosis in MI". The correct legend should state "TIMI, thrombolysis in myocardial infarction".

On page 61 , in line 6 of the first paragraph, note that "unadjusted heart rate" is incorrect, and should be "unadjusted hazard ratio".

On page 62 , the last sentence is incorrectly provided as follows: "Given that the combination of abciximab plus reduceddose fibrinolytic was associated with a significantly higher incidence of major and minor bleeding than treatment with a fibrinolytic [GUSTO- $\mathrm{V}^{76}$ and ASSENT- $3,{ }^{77}$ studies that are sufficiently powered for tolerability endpoints are required before firm conclusions can be drawn regarding the effect of a combination of eptifibatide and reduced-dose fibrinolytic on the incidence of major hemorrhage". The correct sentence is: "Given that the combination of abciximab plus a reduced dose of fibrinolytic was associated with a significantly higher incidence of major and minor bleeding than treatment with a fibrinolytic agent alone [GUSTO- $\mathrm{V}^{76}$ and ASSENT-3 ${ }^{77}$ ] studies that are sufficiently powered for tolerability endpoints are required before firm conclusions can be drawn regarding the effect of a combination of eptifibatide and reduced-dose fibrinolytic".

\section{Publish your work in this journal}

Core Evidence is an international, peer-reviewed open-access journal evaluating the evidence underlying the potential place in therapy of drugs throughout their development lifecycle from preclinical to postlaunch. The focus of each review is to evaluate the case for a new drug or class in outcome terms in specific indications and patient groups.
The manuscript management system is completely online and includes a very quick and fair peer-review system, which is all easy to use. Visit http://www.dovepress.com/testimonials.php to read real quotes from published authors. 